BANGLADESH J CHILD HEALTH 2012; VOL 36 (1): 36-45

\title{
Meeting Micronutrient Requirements for Health and Development: An Update
}

\author{
M JAHANGIR ALAM ${ }^{1}$, R MOBARAK ${ }^{2}$, HS KAMRUL ALAM ${ }^{2}$, M SHAFIUL HAQUE ${ }^{2}$, M ABU TAYAB $^{2}$
}

\section{Introduction}

Despite numerous advances and improvements in child health, malnutrition still remains as one of the main public health challenges of the 21st century, particularly in developing countries ${ }^{1}$. It undermines the survival, growth and development of children and is associated with almost $35 \%$ of all deaths in children under the age of five worldwide. ${ }^{2}$ An estimated 178 million children are stunted globally and an additional 19 million children have severe acute malnutrition (wasting). ${ }^{2}$ Any of these conditions are associated with concomitant micronutrient deficiencies. Among these: vitamin A, Iron, Zinc and lodine deficiencies are the most prevalent in childhood and vitamin $A$ and zinc deficiency associated with an estimated one million child deaths and $9 \%$ of global childhood DALYs (Disability-Associated Life years) ${ }^{2}$. Recent data on the timing of growth retardation and stunting in infants suggest that the onset is commensurate with inappropriate complementary feeding and potentially compounded by maternal undernutrition and intrauterine growth retardation (IUGR), and that the first 24 months represent a critical window of opportunity for intervention ${ }^{3}$. The relationship between micronutrient deficiencies and increased risk of infections and mortality is well established ${ }^{4}$. Several micronutrients play important role in the immune system and are critical in determining the outcome of host microbe interactions ${ }^{5}$ Infections on the other hand are a risk factor for malnutrition as during an episode of an infection, there is a general decrease in nutrients intake, increase losses (e.g. G.l losses, fluid losses etc.) and altered metabolic pathways. This condition is more prevalent among poor children whose micronutrient status is already marginal and they also have high frequency of infectious disease. This leads to a vicious cycle where malnutrition is a health outcome as well as a risk factor for disease and exacerbation of malnutrition ${ }^{6}$. The resulting complex and mutually adverse interactions with infections constitute the major determinants of childhood

1. Associate Professor, BICH, Dhaka Shishu Hospital, Dhaka 2. Assistant Professor, BICH, Dhaka Shishu Hospital, Dhaka Correspondence: Dr. M Jahangir Alam morbidity and mortality among the underprivileged preschool children in several developing countries ${ }^{7}$. The purpose of this paper was to summarize the current knowledge on micronutrient deficiencies and their role in reducing morbidity and mortality during childhood.

\section{Vitamin A}

Vitamin A has been termed as an anti-infectious agent plays an important role in visual system. ${ }^{8}$ Vitamin $A$ deficiency (VAD) impairs numerous body functions and can lead to many adverse health consequences including xerophthalmia (dry eyes), infections, morbidity, mortality, sub-optimal physical growth and anemia $^{8}$. VAD is a major nutritional public health problem in the developing world. According to the latest report of the $\mathrm{WHO}$, globally about 190 million preschool-aged children and 19.1 million pregnant women are vitamin A deficient (i.e. serum retinol < $0.70 \mathrm{imol} / /)^{9}$. This corresponds to $33.3 \%$ of preschoolaged children and $15.3 \%$ of pregnant women in populations at risk of VAD. According to current estimates, 122 countries are classified as having a moderate to severe public health problem based on biochemical VAD in preschool-aged children, and 88 countries based on biochemical VAD in pregnant women $^{9}$. Xerophthalmia, resulting from VAD is the primary preventable cause of blindness and of the world's children with xerophthalmia, nearly half reside in South or South-East Asia, of whom more than $85 \%$ live in India ${ }^{10}$. About 5.2 million preschool-aged children and 9.8 million pregnant women suffer from night blindness, which represents $0.9 \%$ and $7.8 \%$ of the population at risk of VAD, respectively. The estimates show that Africa and South-East Asia contain the highest proportions of preschool-aged children and pregnant females with biochemical VAD and night blindness ${ }^{9}$. Evidence from community trials has shown that vitamin A supplementation (VAS) reduces all-causes of mortality and diarrhea and measles specific mortality ${ }^{11}$. It also reduces incidence of measles and diarrhea infection ${ }^{11}$. VAS has also been shown to reduce prevalence of xerophthalmia and night blindness ${ }^{11}$. VAS as an adjunct in the treatment of measles has been shown to reduce 
mortality, pneumonia-specific mortality and incidence of croup ${ }^{12}$. World health organization recommends two annual high-dose supplements of vitamin A for every child at risk of VAD ${ }^{13}$. Since 1998 , large vitamin A supplementation programs are in place in about 193 UNICEF targeted countries to deliver the required dose of vitamin $A^{14}$. It can be noted that in 1999 , just $16 \%$ of children in these countries received full vitamin A supplementation while in 2005 this number increased to $72 \%{ }^{15}$.

\section{Vitamin A supplementation:}

The WHO recommends VAS for young children at a dose of $50,000 \mathrm{IU}$ for infants $<6$ months of age, 100,000 IU for infants $6-12$ months of age and 200,000 IU for children over 12 months of age, every 4 to 6 months (WHO 1997) ${ }^{16}$. The international community, recommends for a target of all children between the ages of 6 months and 5 years, in all countries where over 70 in 1,000 children die before the age of 5 , as this is the internationally accepted proxy to indicate that vitamin A deficiency is a public health problem ${ }^{17}$. However, worldwide, a large proportion of children receiving it are neither vitamin A deficient nor stunted nor wasted. The effect of such a public health policy on this population needs to be carefully assessed.

\section{Mortality outcomes: VAS in $>\mathbf{6}$ month old children} In Indonesian children who received massive dose of vitamin A supplements, had a 34 percent lower mortality from all causes than those not receiving the supplement ${ }^{18}$. A meta analysis of these initial studies concluded that VAS to measles hospitalized patients was highly protective for mortality. And, when given periodically to children at the community level, it decreased overall mortality ${ }^{19}$.

\section{Mortality outcomes: Children 1-5 months of age}

Studies where children were supplemented with vitamin A between 1 and 5 months of age did not show any positive effect on overall mortality ${ }^{20}$. Plausible explanations for these findings have focused on differences in environmental influences on this age group in relation to older infants (e.g. the protection of breast feeding against malnutrition and infection) Whether this could be explained by the interactions with vaccines given at this age, such as inactivated DTP vaccine, with vitamin A need to be further investigated

\section{Vitamin A in newborns}

In developing countries, infants are born with low stores of vitamin A and depend on external sources. Sometimes breastfeeding is not enough and newborns and infants need VAS; however, results obtained with this strategy have been contradictory. Studies from Bangladesh $^{21}$, India ${ }^{22}$, and Indonesia ${ }^{23}$, have shown reductions in all-cause mortality $(15 \%, 22 \%$ and $63 \%$, respectively) in infants who received VAS relative to controls. Also, VAS has shown to reduce diarrhea case-fatality rates and the incidence of fever ${ }^{24}$. One study performed in Nepal showed no overall effect on early infant mortality and there was a tendency for the relative risk of mortality among vitamin A recipients to rise with improved nutritional status ${ }^{25}$. Trials in Africa, in countries like Guinea-Bissau ${ }^{26}$, and Zimbabwe ${ }^{27}$ suggest a lack of benefit from vitamin $A$ supplementation. Many speculations have been so far formulated in order to understand these controversial results. A recent meta regression analysis performed by Rotondi et $\mathrm{al}^{28}$, suggests that vitamin A supplementation to neonates within the first two days of life may confer benefit, specially in regions where the prevalence of vitamin A deficiency is $22 \%$ or more among pregnant women. This is an important finding given the current debate as to whether giving neonates vitamin A supplements helps reduce infant mortality in populations where endemic vitamin $A$ deficiency and high infant mortality exist. However, not all neonatal VAS trials support a strong association between vitamin $A$ status and baseline infant mortality, and the VAS effect. Thus, in the Indonesian trial mothers had a good vitamin A status and infants a very good effect of VAS ${ }^{10}$.

Morbidity outcome: Diarrhea, LRTI and measles In relation to morbidity, another controversy arises: to what extent is the decrease in mortality due to reduction in morbidity from diarrhea and respiratory infection (other than measles). One study in India, with measles vaccinated and not severely malnourished children, concluded that VAS did not reduce respiratory and diarrheal morbidity as compared to the placebo controls ${ }^{29}$.

Even more controversial, VAS has been shown, not only not be beneficial, but detrimental in pediatric population. In a blinded, randomized controlled trial (RCT) performed in Mexico ${ }^{30}$, where measles vaccination coverage is very high and mortality in children $<5$ years has been estimated in 17.4/1000 
live births (2009) (Information from DGIS, SS Mexico), VAS to infants $6-15$ mo was associated with a $27 \%$ increase in diarrheal disease and a $23 \%$ increase in cough with fever. The authors postulated that the increase in diarrhea in this study might reflect the effect of VAS to down-regulate the Th1 response, which protects against rotavirus. Similarly, they speculated that negative respiratory outcomes might be explained by the adverse effect of VAS in respiratory syncytial virus infections ${ }^{31}$. A meta analysis by Chen et $\mathrm{al}^{32}$ concluded that VAS does not have a universal protective effect as prophylaxis for LRTI in children; indeed, three studies showed an increase in respiratory morbidity associated with VAS.

\section{Folate and vitamin B12: function and importance in cognitive development \\ Biochemical Function of Folate and Vitamin B12:}

The importance of folate and vitamin B12 for healthy neurological development and function is unquestioned. As essential co-factors for one-carbon metabolism, folate and vitamin B12 are required for biological methylation and DNA synthesis. Methylation activity is essential for many processes that are critical for central nervous function, such as the epigenetic regulation of gene expression by DNA and histone methylation, the methylation of myelin basic protein and membrane phosphatidylcholine, the synthesis of hormones and neurotransmitters such melatonin and epinephrine, and the inactivation of dopamine and catecholamines. Folate (in the form of 5methyltetrahydrofolate) and vitamin B12 are required in all tissues to maintain adequate cellular methionine, which in turn is converted to S-adenosylmethionine (SAM) the universal methyl-donor for these reactions. Folate and B12 deficiency inhibit methylation and cause homocysteine to accumulate in circulation. Homocysteine may be cytotoxic and mildly elevated plasma homocysteine is associated with increased risk of neurodegnerative and cardiovascular disease. By increasing choline utilization or by depleting membrane phosphatidylcholine, folate deficiency might also indirectly limit the synthesis of the key neurotransmitter acetylcholine. Folate is needed to synthesize thimidylate and purine nucleotides. Thus, folate deficiency can compromise DNA replication and integrity. Vitamin B12 serves as a coenzyme for methylmalonyl-CoA mutase which catalyzes the final step in the mitochondrial degradation of odd chain fatty acids and branched amino acids. These biochemical effects of deficiency can be theoretically linked to the observed neuropathological, cognitive and developmental abnormalities that are associated with deficiency of these vitamins ${ }^{33}$.

Neurological consequences of acquired and congenital defects in one-carbon metabolism

The importance of folate and vitamin B12 for healthy brain development and function is evident. Severe acquired deficiencies of vitamin B12 and folate manifest with either haematological or neurological abnormalities or a combination of both ${ }^{34}$. The primary neurological feature is a progressive neuropathy in which sensation and motor control are gradually lost, typically beginning with the lower limbs ${ }^{35}$. In addition, these conditions are often accompanied by behavioral changes ranging from mild irritability to severe depression, hallucinations, confusion and memory loss $^{36}$.

Symptoms of clinical deficiency can be treated with intramuscular injections and high dose oral supplementation, leading to hematologic and neurologic recovery; however in the long term, resolving the deficiency and acute pathology does not guarantee full restoration of cognitive development ${ }^{37}$.

\section{Sub-clinical deficiencies in CNS development and aging}

The neuropathology common to both congenital and severe acquired vitamin B12 and folate deficiencies include increased risk of neural tube defects (NTDs) among children born to mothers with low folate status, and increased risk of cognitive impairment, depression, Alzheimer's disease and stroke among older adults.

With respect to aging, the association between low B-vitamin status and increased risk of neurodegenerative disease has been extensively reviewed ${ }^{38}$. Data from over 100 observational cross sectional and prospective studies, encompassing over 50,000 subjects in total, provides compelling evidence for the association with approximately $90 \%$ of the studies reporting significant associations and the remainder not. Taken together, they provide the basis for the tenable hypothesis that "low-normal intake or blood concentrations of B-vitamins (folate, B12 and B6) and/or moderately elevated plasma total homocysteine increase the risk of brain atrophy and developing cognitive impairment in the elderly ${ }^{33,38}$. Early observations that poor folate status is associated with increased risk of spina bifida and anencephaly led to highly successful clinical trials in which use of 
periconceptual folic acid supplements reduced the risk of incident NTDs by as much as 50 percent or more ${ }^{39}$.

Folate and B12 supplementation and cognitive development

The upper limit of folate intake for adults was conservatively set at $1 \mathrm{mg}$ per day out of concern for the possibility that in individuals with frank B12 deficiency, high folate might either exacerbate the symptoms or "mask" the associated anemia, delaying early detection and treatment and thus allowing it to progress. Cross sectional data from the NHANES and SALSA cohorts show that the metabolic effects of vitamin B12 deficiency are more pronounced in adults with high folic acid intake. Irrespective of B12 status, high folic acid intake has also been observed to associate with more rapid cognitive decline in older adults and with decreased immune function in older post-menopausal women ${ }^{40,41}$.

\section{Iron}

Iron is an essential mineral for human development and function. It is required for Hemoglobin and is critical for motor and cognitive development in childhood, and for physical activity in all humans ${ }^{42}$. Iron is also critical to the health of a pregnant mother and her unborn child. A woman needs more iron during pregnancy because the fetus and placenta both need additional iron. Iron supplementation during pregnancy, lowers the risk of maternal mortality due to haemorrhage, the cause of more than 130,000 maternal deaths each year ${ }^{14}$. Supplementation also helps to lower the risks of premature birth and low birth weight. Studies have shown that infants with anaemia caused by iron deficiency have lower mental scores and lower motor scores than infants without anaemia ${ }^{43}$.

The influence of inflammatory disorders and infection on iron absorption and the efficacy of iron fortified foods

\section{Introduction}

Approximately $90 \%$ of daily iron needs can be met by the re-utilization of red cell iron after the breakdown of circulating red cells at the end of their natural life span. Although there is no physiological mechanism for active iron excretion from the body, there are obligatory iron losses from skin, intestine and urinary tract and additional losses during menstruation in women of child bearing age. To maintain iron balance, obligatory and menstrual iron losses, plus the iron required for growth in infants, children, and adolescents must come from the diet. This represents about 1-2 mg of absorbed iron per day. Many young women, infants and children fail to meet their iron needs from diet and these population groups make up the majority of the 2 billion people worldwide estimated to be iron deficient ${ }^{44}$. The situation is worse in the developing world due to low iron bioavailability from plant based diets and iron deficiency has more serious negative health and economic consequences including poor pregnancy outcome, poor cognitive development in children, and decreased physical performance and productivity 45 .

Iron fortified foods often contain inhibitors of iron absorption such as phytic acid and polyphenols in cereal and legume foods ${ }^{46}$ and calcium in milk products $^{47}$. In order to overcome the negative effects of these inhibitors, the food manufacture usually adds ascorbic acid, although NaFeEDTA and phytase can also be added ${ }^{48}$.

There is an inverse correlation between iron status and iron absorption ${ }^{49}$ with a $50 \%$ decrease in iron stores doubling of iron absorption, although the magnitude of the inhibitory or enhancing effects are independent of iron status. Genetic disorders, nutritional deficiencies, infection and inflammation can also influence iron absorption ${ }^{50}$. Vitamin A deficiency can influence several stages of iron metabolism and riboflavin deficiencies may decrease iron incorporation into hemoglobin. Chronic inflammation ${ }^{51}$ and obesity 52 increase hepcidin expression and would be expected to decrease iron absorption ${ }^{53}$.

Iron metabolism during infection and inflammation Iron needed for new red cell synthesis and for replenishing iron enzymes and myoglobin is transported to the bone marrow or body tissues via transferrin in the plasma. The passage of iron into the plasma is mediated via the transport protein ferroprotein situated on the cell membrane ${ }^{54}$ and its entry is strictly controlled by the regulatory hormone, hepcidin. This protein is secreted by the liver when iron status is adequate and inhibits the transport of iron into the plasma from both the macrophages and the intestinal cells ${ }^{55}$. Hepcidin binds ferroprotein at the cell membrane, causing internalization and degradation ${ }^{56}$ and when iron status is low, hepcidin release from the liver is decreased and iron absorption is maximized.

The innate immune response to microbial infection is to increase hepcidin via an inflammatory response and to restrict microbial growth by restricting the entry 
of iron into the plasma ${ }^{57}$. The anemia of infection results from an interruption in the recycling of red cell iron. Macrophage iron is not released resulting in insufficient iron for erythropoiesis. The outcome of many infectious diseases depends on preventing the invading pathogen from obtaining its iron supply, and provision of high iron doses to an infected patient can worsen the infection. In addition to preventing iron release from the macrophage, the inflammatory response would also be expected to prevent iron release from the mucosal cell and thus restrict iron absorption.

\section{Obesity and overweight in relation to iron absorption and the efficacy of iron fortified foods}

American national surveys have consistently shown that overweight toddlers, children, adolescents and adults are more likely to be iron deficient than their normal weight counterparts and recent evidence suggests that adiposity related inflammation may play a central role through its regulation of hepcidin ${ }^{52}$. In a recent Swiss study, overweight children were reported to consume similar amounts of bioavailable iron as normal weight children but have a lower iron status, higher serum hepcidin and higher subclinical inflammation as measured by IL-6 and C-reactive protein $(\mathrm{CRP})^{58}$.

\section{Zinc}

Zinc is the second most abundant transition metal in humans after iron. It is an essential part of about 100 specific enzymes and also serves as structural ions in transcription factors ${ }^{59}$. The association of zinc deficiency in children with growth retardation and hypogonadism was first described in 1963 from Iran ${ }^{60}$ and it is now well established from animal and human studies that zinc plays a critical role in cellular growth, cellular differentiation and metabolism ${ }^{61}$ and in turn promotes immunity, resistance to infection, and the growth and development of the nervous system ${ }^{60}$. Although zinc deficiency is increasingly being recognized as a widespread problem, there is very limited nationally representative data on the magnitude and severity of this deficiency ${ }^{62}$. Some of this is due in part to the lack of reliable biomarkers of zinc status. Recently, Wuehler et al., using data from national food balance sheets compiled by the Food and Agricultural Organization, estimated that $20 \%$ of the world's population is at risk of low zinc intakes ${ }^{63}$. The global prevalence of low intakes by region indicates that 26 $\%$ of population in South Asia and $28 \%$ in Sub-Saharan
Africa are at risk deficiency ${ }^{64}$. Therapeutic zinc supplementation as an adjunct in the treatment of diarrhea has been shown to reduce the duration of acute diarrhea by 0.5 days and that of persistent diarrhea by 0.68 days. Preventive zinc supplementation reduces incidence of diarrhea by $20 \%$ and that of pneumonia by $15 \% 65$. Preventive zinc supplementation has been shown to reduce rate of stunting as well ${ }^{66}$. In 2004, WHO and UNICEF formulated a new recommendation to administer zinc for 10 to 14 days as an adjunct treatment for diarrhea, along with low-osmolarity oral rehydration solutions (ORS) and continuation of feeding ${ }^{67}$. Since then WHO and UNICEF in collaboration with USAID and Johns Hopkins University has worked to ensure the availability of zinc products ${ }^{68}$ and about 91 million tablets had been provided in year $2008^{69}$. Despite all these efforts zinc supplementation is not part of national programs around the globe. Only 46 countries have adopted zinc policy as part of their national child health policy ${ }^{70}$. It is therefore required to scale up the zinc supplementation and it should be incorporated into national diarrhea management policy.

\section{lodine}

lodine is the key element required for thyroid hormone synthesis, and is also important for brain development during fetal and early years of life ${ }^{70}$. Children born to iodine-deficient mothers may appear normal at birth but might have suffered brain damage and loss in IQ points, affecting their ability to develop to their full potential. These seemingly normal children will later have difficulty learning in school and staying in school. It has been shown that in communities where iodine intake is sufficient, average IQ is shown to be on average 13 points higher than in iodine deficient communities $^{70}$. According to an estimate about 2 billion people have insufficient iodine intake around the globe and about $31.5 \%$ of school-age children (266 million) have insufficient iodine intake ${ }^{71}$. Salt iodization is one of the exemplary success stories of food fortification offering great benefits for the intellectual health of nations that have embraced it ${ }^{72}$. Thirty-four developing countries have achieved the universal salt iodization goal, and an additional 38 countries are considered 'on track' for elimination of iodine deficiency disorders ${ }^{72}$. Despite this progress, many countries are lagging far behind. Twenty-four countries have experienced no growth in coverage rates or have even experienced a decline since the mid-1990s ${ }^{72}$. 
Intervention Strategies to Address Multiple Micronutrient Deficiencies in Early Childhood Introduction

Micronutrient deficiencies are widespread and are a major global health problem worldwide ${ }^{73}$. World Health Organization (WHO) estimates that more than 2 billion people are deficient in key vitamins and minerals, particularly vitamin $\mathrm{A}$, iodine, iron and zinc. Most of these people live in low income countries and are typically deficient in more than one micronutrient. ${ }^{74}$ Globally, about 1.62 billion people are anemic with the highest prevalence in preschool age children (47\%) and the second highest in pregnant women (42\%). According to the latest report of the $\mathrm{WHO}$, globally about 190 million preschool-aged children and 19.1 million pregnant women are vitamin A deficient (i.e. serum retinol $<0.70$ ìmo $\mathrm{I} / \mathrm{I})^{75}$. Approximately 100 million women of reproductive age suffer from iodine deficiency ${ }^{76}$. An estimated $82 \%$ of pregnant women worldwide have inadequate intakes of zinc to meet the normative needs of pregnancy ${ }^{77}$. Suboptimal vitamin B6 and B12 status has been observed in many developing countries ${ }^{78}$.

\section{Maternal Micronutrient Supplementation during Pregnancy}

In 1999 the UNICEF/WHO/UN University proposed a prenatal supplement UNIMAPP containing fifteen micronutrients, including iron and folic acid which could provide one recommended daily allowance of each and potentially replace standard iron-folate supplements for pregnant women in low and middle income countries. A Cochrane review on the subject ${ }^{81}$ indicated that compared to iron-folate, multiple micronutrient supplementation had comparable effect on maternal anemia and had a significant effect on incidence of low birth weight (LBW) babies and that of small for gestational age babies

\section{Multiple micronutrient supplementation among children at risk of deficiencies}

As deficiencies of important micronutrients like iron, zinc vitamin Aetc. are prevalent in children in developing countries, efforts have been made to supplement infants and children with multiple micronutrients. A review by Ramakrishnan et al ${ }^{81}$. based on 20 randomized trials, has shown that multiple micronutrient interventions improved linear growth. Another review by Allen et al ${ }^{80}$. has shown that in children, MMN interventions resulted in small but significantly greater improvements in length or height and weight, hemoglobin), serum zinc serum retinol and motor development. In addition to these benefits, multiple micronutrients have a beneficial effect on mental development of children. A review by Eilander et al. ${ }^{82}$ has shown that MMN supplementation during childhood has a significant effect on academic

\section{Conclusions}

Micronutrients like vitamin A, Vit B12, foliccid, iron, zinc and iodine are important for growth and survival of children. Given the wide prevalence of multiple micronutrient deficiencies in malnourished children in developing countries, the challenge is to implement intervention strategies that combine appropriate infant and young child feeding with micronutrient interventions at scale. Emerging data from community intervention trials now provide evidence that this is both tangible and can lead to alleviation of childhood under nutrition. Multiple micronutrients supplementation during pregnancy and early childhood in populations at risk is an effective way of prevention of micronutrient deficiencies. Further studies are needed on cost effectiveness and delivery strategies in health system settings.

\section{References:}

1. Khan Y, Bhutta ZA. Nutritional deficiencies in the developing world: current status and opportunities for intervention. Pediatr Clin North Am. 2010; 57(6): 140941.

2. Black RE, Allen LH, Bhutta ZA, Caulfield LE, de Onis M, Ezzati M, et al. Maternal and child undernutrition: global and regional exposures and health consequences. Lancet. 2008; 371(9608): 24360.

3. Victora CG, de Onis M, Hallal PC, Blossner M, Shrimpton R. Worldwide timing of growth faltering: revisiting implications for interventions. Pediatrics. 2010; 125(3): e473 80.

4. Bhutta ZA. Micronutrient needs of malnourished children. Curr Opin Clin Nutr Metab Care. 2008; 11(3): 30914.

5. Katona P, Katona Apte J. The interaction between nutrition and infection. Clin Infect Dis. 2008; 46(10): 15828.

6. Khan YP, Yakoob MY, Bhutta ZA. Maternal mineral and vitamin supplementation in pregnancy. Expert Reviews in Obstetrics \& Gynecology. 2010; 5(2): 24156. 
7. UNICEF. Tracking progress on child and maternal nutrition. New York; 2009 [updated 2009; cited 15 Jan 2011]; Available from: http:// www.unicef.org/publications/index_51656.html.

8. Bates CJ. Vitamin A. Lancet. 1995; 345(8941): 315.

9. WHO. Global prevalence of vitamin A deficiency in populations at risk 1995-2005. WHO Global Database on Vitamin A Deficiency. Geneva: World Health Organization; 2009|.

10. West KP, Jr. Extent of vitamin A deficiency among preschool children and women of reproductive age. J Nutr. 2002;132(9 Suppl): 2857S 66S.

11. Imdad A, Herzer K, Mayo Wilson E, Yakoob MY, Bhutta ZA. Vitamin A supplementation for preventing morbidity and mortality in children from 6 months to 5 years of age. Cochrane Database Syst Rev. 2010;12:CD008524.

12. Yang $\mathrm{HM}, \mathrm{Mao} \mathrm{M}$, Wan $\mathrm{C}$. Vitamin A for treating measles in children. Cochrane Database of Systematic Reviews 2005, Issue 4. Art. No.: CD001479. DOI: 10.1002/ 14651858.CD001479.pub3.

13. WHO. Vitamin A supplements: A guide to their use in prevention and treatment of vitamin $A$ deficiency and xerophthalmia. Geneva: World Health Organization; 1997.

14. UNICEF. The State of the World's Children 2009, New York, UNICEF.

15. UNICEF. Vitamin A Supplementation:A Decade of Progress, New York, UNICEF. 2007.

16. WHO. Vitamin A supplements; $A$ guide to their use in prevention and treatment of vitamin $A$ deficiency and xerophthalmia. Geneva: World Health Organization, 1997.

17. United Nations Children s Fund (UNICEF). Vitamin A supplementation: Progress for child survival. Working paper prepared by UNICEF nutrition section. New York: UNICEF, 2005.

18. Sommer A, Tarwotjo I, Djunaedi E, West KP Jr, Loeden AA, Tilden R, et al. Impact of vitamin A supplementation on childhood mortality. Lancet 1986, 1: 1169-73.

19. Fawzi WW, Chalmers TC, Herrera MG et al. Vitamin A supplementation and child mortality: a meta-analysis. Journal of the American Medical Association. 1993; 269: 898-903.

20. Rahman MM, Mahalanabis D, Wahed MA, Islam MA, Habte D. Administration of 25,000 IU vitamin A doses at routine immunisation in young infants. Eur J Clin Nutr. 1995;49:439-45.

21. Klemm RD, Labrique AB, Christian P, Rashid M, Shamim AA, Katz J, et al. Newborn vitamin A supplementation reduced infant mortality in rural Bangladesh. Pediatrics. 2008;122:e242-50. doi: 10.1542/peds.2007-3448.

22. Rahmathullah L, Tielsch JM, Thulasiraj RD, Katz J, Coles c, Devi S, et al. Impact of supplementing newborn infants with vitamin $A$ on early infant mortality: community based randomised trial in southern India. BMJ. 2003;327:254. doi: 10.1136/ bmj.327.7409.254.

23. Humphrey JH, Agoestina T, Wu L, Usman A, Nurachim M, Subardja D, et al. Impact of neonatal vitamin A supplementation on infant morbidity and mortality. J Pediatr. 1996;128:489-96. doi: 10.1016/S0022-3476(96)70359-1.

24. Tielsch JM, Rahmathullah L, Thulasiraj RD, Katz J, Coles C, Sheeladevi S, et al. Newborn vitamin A dosing reduces the case fatality but not incidence of common childhood morbidities in South India. J Nutr. 2007;137:2470-4.

25. West Jr KP, Katz J, Shrestha SR, LcClerq SC, Khatrv SK, Pradhan EK, et al. Mortality of infants $<6$ mo of age supplemented with vitamin A: a randomized, double-masked trial in Nepal. Am J Clin Nutr. 1995;62:143-8.

26. Benn CS, Diness $B R$, Roth $A$, Nante $E$, Fisker $A B$, Lisse IM, et al. Effect of 50,000 IU vitamin A given with $B C G$ vaccine on mortality in infants in Guinea-Bissau: randomised placebo controlled trial. BMJ. 2008;336:1416-20. doi: 10.1136/ bmj.39542.509444.AE. [

27. Malaba LC, Iliff PJ, Nathoo KJ, Marinda E, Moulton LH, Zijenah LS, et al. Zvitambo Study Group Effect of postpartum maternal or neonatal vitamin A supplementation on infant mortality among infants born to HIV-negative mothers in Zimbabwe. Am J Clin Nutr. 2005;81:454-60.

28. Rotondia MA, Khobzia N. Vitamin A supplementation and neonatal mortality in the developing world: a meta-regression of cluster- 
randomized trials Bull World Health Organ. 2010 September 1; 88(9): 697-702. Published online 2010 April 16. doi: 10.2471/BLT.09.068080. PMCID: PMC2930359 Copyright (c) World Health Organization (WHO) 2010.

29. Ramakrishnan U, Latham MC, Abel R, Frongillo EA. Vitamin A Supplementation and Morbidity Among Preschool Children in South India. Am J Clin Nutr 1995;61: 1295-1303,1995.

30. Long KZ, Montoya Y, Hertzmark E, Santos JI, Rosado JL. A double-blind, randomized, clinical trial of the effect of vitamin A and zinc supplementation on diarrheal disease and respiratory tract infections in children in Mexico City, Mexico Am J Clin Nutr 2006; 83: 693-700.

31. Bresee JS, Fischer M, Dowell SF, Johnston BD, Biggs VM, Levine RS, et al. Vitamin A therapy for children with respiratory syncytial virus infection: a multicenter trial in the United States. Pediatr Infect Dis J 1996;15:777-82.

32. Chen H, Zhuo Q, Yuan W, Wang J, Wu T. Vitamin A for preventing acute lower respiratory tract infections in children up to seven years of age. Cochrane Database of Systematic Reviews 2008, Issue 1. Art. No.: CD006090. DOI: 10.1002/ 14651858.CD006090.pub2.

33. Selhub J, Bagley LC, Miller J, Rosenberg IH. B vitamins, homocysteine, and neurocognitive function in the elderly. Am J Clin Nutr 2000; 71 : 614S-620S.

34. Gross JS, Weintraub NT, Neufeld RR, Libow LS. Pernicious anemia in the demented patient without anemia or macrocytosis. Acase for early recognition. Journal of The American Geriatrics Society $1986 ; 34: 612-4$.

35. Weir DG, Scott JM. The biochemical basis of the neuropathy in cobalamin deficiency. Balliere's Clinical Haematology 1995; 8: 479-497.

36. Allen RH, Stabler SP, Lindenbaum J. Relevance of vitamins, homocysteine and other metabolites in neuropsychiatric disorders. Eu J Pediatr1998;157 (Suppl 2): S122-6.

37. Graham SM, Arvela OM, Wise GA. Long-term neurologic consequences of nutritional vitamin B12 deficiency in infants. J Pediatr 1992;121(5 Pt 1):710-4.
38. Smith AD. The worldwide challenge of the dementias: a role for $B$ vitamins and homocysteine? Food Nutr Bull 2008; 29(2 Suppl): S143-72.

39. Heseker HB, Mason JB, Selhub J, Rosenberg $\mathrm{IH}$, Jacques PF. Not all cases of neural-tube defect can be prevented by increasing the intake of folic acid. Br J Nutr 2009; 102: 173-80.

40. Troen AM, Mitchell B, Sorensen B, Wener Hm, Johnston A, Wood B et al. Unmetabolized folic acid in plasma is associated with reduced natural killer cell cytotoxicity among postmenopausal women. J Nutr 2006;136(1):189-94.

41. Fagiolini $M$, Jensen $C L$, Champagne FA. Epigenetic influences on brain development and plasticity. Curr Opin Neurobiol 2009;19(2):20712.

42. Stoltzfus RJ, Mullany L, Black RE. Iron deficiency anaemia. In: Ezzati M, Lopez AD, Rodgers A, Murray CLJ, editors. Comparative quantification of health risks: global and regional burden of disease attributable to selected major risk factors. Geneva: World Health Organization; 2004. p. 163209.

43. Walker SP, Wachs TD, Gardner JM, Lozoff B, Wasserman GA, Pollitt E, et al. Child development: risk factors for adverse outcomes in developing countries. Lancet. 2007; 369(9556): 14557.

44. WHO/FAO. Guidelines on food fortification with micronutrients. Geneva: World Health Organization; 2006.

45. Zimmermann MB, Hurrell RF. Nutritional iron deficiency. Lancet 2007;370:511-20.

46. Hallberg L, Brune M, Rossander L. Iron absorption in man: ascorbic acid and dosedependent inhibition by phytate. Am J Clin Nutr 1989; 49: 140-4.

47. Hallberg L, Brune M, Erlandsson M, Sandberg AS, Rossander-Hulten L. Calcium: effect of different amounts on nonheme- and heme-iron absorption in humans. Am J Clin Nutr 1991;53:112-9. 10

48. Troesch B, Egli I, Zeder C, Hurrell RF, de Pee S, Zimmermann MB. Optimization of a phytasecontaining micronutrient powder with low amounts of highly bioavailable iron for in-home 
fortification of complementary foods. American Journal of Clinical Nutrition 2009;89:539-44.

49. Cook JD, Dassenko SA, Lynch SR. Assessment of the role of nonheme-iron availability in iron balance. Am J Clin Nutr 1991;54:717-22.

50. Hurrell R, Egli I. Iron bioavailability and dietary reference values. Am J Clin Nutr 2010;91:1461s$7 s$.

51. Nemeth E, Valore EV, Territo M, Schiller G, Lichtenstein A, Ganz T. Hepcidin, a putative mediator of anemia of inflammation, is a type II acute-phase protein. Blood 2003;101:2461-3.

52. Cepeda-Lopez AC, Aeberli I, Zimmermann MB. Does obesity increase risk for iron deficiency? A review of the literature and the potential mechanisms. Int J Vitam Nutr Res 2010;80:26370.

53. Cercamondi Cl, Egli IM, Ahouandjinou E, Dossa , Zeder C, Salami L, et al. Afebrile Plasmodium falciparum parasitemia decreases absorption of fortification iron but does not affect systemic iron utilization a double stable-isotope study in young Beninese women. Am J Clin Nutr 2010;92:138592.

54. Donovan A, Lima CA, Pinkus JL, Pinkus GS, Zon LI, Robine $S$, et al. The iron exporter ferroportin/SIc40a1 is essential for iron homeostasis. Cell Metab 2005; 1: 191-200.

55. Ganz T. Hepcidin - a regulator of intestinal iron absorption and iron recycling by macrophages. Best Pract Res Clin Haematol 2005;18:171-82.

56. Nemeth E, Tuttle MS, Powelson J, Pinkus GS, Zon LI, robine S, et al. Hepcidin regulates cellular iron efflux by binding to ferroportin and inducing its internalization. Science 2004; 306: 2090-3.

57. Wander K, Shell-Duncan B, McDade TW. Evaluation of iron deficiency as a nutritional adaptation to infectious disease: an evolutionary medicine perspective. Am J Hum Biol 2009; 21: 172-9.

58. Aeberli I, Beljean N, Lehmann R, l'Allemand D, Spinas GA, Zimmermann MB. The increase of fatty acid-binding protein $\mathrm{AP} 2$ in overweight and obese children: interactions with dietary fat and impact on measures of subclinical inflammation. Int J Obes (Lond) 2008;32:1513-20.
59. Prasad A. Biochemistry of Zinc. New York: Plenum Press. 1993.

60. Moynahan EJ. Letter: Acrodermatitis enteropathica: a lethal inherited human zinc deficiency disorder. Lancet. 1974; 2(7877): 399 400.

61. Prasad AS. Discovery of human zinc deficiency and studies in an experimental human model. Am J Clin Nutr. 1991; 53(2): 40312.

62. Ramakrishnan U. Prevalence of micronutrient malnutrition worldwide. Nutr Rev. 2002; 60(5 Pt 2): S46 52.

63. Wuehler SE, Peerson JM, Brown KH. Use of national food balance data to estimate the adequacy of zinc in national food supplies: methodology and regional estimates. Public Health Nutr. 2005; 8(7): 8129.

64. Walker CL, Black RE. Zinc for the treatment of diarrhoea: effect on diarrhoea morbidity, mortality and incidence of future episodes. Int J Epidemiol. 2010 Apr;39 Suppl 1:i63 9.

65. Lassi ZS, Haider BA, Btta ZA. Zinc supplementation for the prevention of pneumonia in children aged 2 months to 59 months. Cochrane Database Syst Rev. 2010;12:CD005978.

66. Imdad A, Bhutta ZA. Effect of preventive zinc supplementation on linear growth in children under 5 years of age in developing countries: a meta analysis of studies for input to the Lives Saved Tool. BMC Public Health (in press). 2011.

67. WHO/Unicef. Clinical management of acute diarrhoea. 2004 [updated 2004; cited Feb 28 2011]; Available from: http://www.who.int/ child_adolescent_health/documents/ who_fch_cah_04_7/en/index.html.

68. Fischer Walker CL, Fontaine O, Young MW, Black RE. Zinc and low osmolarity oral rehydration salts for diarrhoea: a renewed call to action. Bull WHO. 2009 Oct;87(10):780 6.

69. UNICEF. Zinc for management of diarrhoea: Consultation with pharmaceutical manufacturers, Presentation 2008 [updated 2008; cited Feb 28 2011]; Available from: origin www.unicef.org/supply/files/4 a _Zinc_Jan_Komrska_and_Francisco_Blanco(1).pdf. 
70. Zimmermann MB, Jooste PL, Pandav CS. lodine deficiency disorders. Lancet. 2008 Oct 4;372(9645):1251 62.

71. de Benoist B, McLean E, Andersson M, Rogers L. lodine deficiency in 2007: global progress since 2003. Food Nutr Bull. 2008 Sep;29(3):195 202.

72. UNICEF. Sustainable Elimination of lodine Deficiency: Progress since the 1990 World Summit for Children, New York, UNICEF. 2008.

73. Tulchinsky TH. Micronutrient Deficiency Conditions: Global Health Issues. Public Health Reviews, Vol 32, No 1, 243 255. 2010;32(1):243 55.

74. WHO. World health report.Geneva: World Health Organization. 2000.

75. WHO. Global prevalence of vitamin A deficiency in populations at risk 1995-2005. WHO Global Database on Vitamin A Deficiency. Geneva: World Health Organization; 2009 Contract No.: Document Number|.

76. Caulfield LE, Zavaleta N, Shankar AH, Merialdi M. Potential contribution of maternal zinc supplementation during pregnancy to maternal and child survival. Am J Clin Nutr. 1998 Aug;68 (2Suppl):499S 508S.
77. McLean E, de Benoist B, Allen LH. Review of the magnitude of folate and vitamin B12 deficiencies worldwide. Food Nutr Bull. 2008; 29 (2 Suppl): S38 51.

78. UNICEF, WHO, and UNU. Composition of a multi micronutrient supplement to be used in pilot programmes among pregnant women in developing countries. New York: UNICEF. 1999.

79. Haider BA, Bhutta ZA. Multiple micronutrient supplementation for women during pregnancy. Cochrane Database Syst Rev. 2006(4): CD004905.

80. Allen LH, Peerson JM, Olney DK. Provision of multiple rather than two or fewer micronutrients more effectively improves growth and other outcomes in micronutrient deficient children and adults. J Nutr. 2009;139(5):1022 30.

81. Ramakrishnan U, Nguyen P, Martorell R. Effects of micronutrients on growth of children under $5 \mathrm{y}$ of age: meta analyses of single and multiple nutrient interventions. Am J Clin Nutr. 2009; 89(1): 191203.

82. Eilander A, Gera T, Sachdev HS, Transler C, van der Knaap HC, Kok FJ. Multiple micronutrient supplementation for improving cognitive performance in children: systematic review of randomized controlled trials. Am J Clin Nutr. 2010; 91(1): 11530. 